\section{GENETICS AND THE BIOLOGICAL FRONT}

Advances in Genetics

Vol. 12. Edited by E. W. Caspar and J. M. Thoday. Pp. viii +388 . (New York: Academic Press, Inc.; London: Academic Press, Inc. (London), Ltd., 1964.) 100s.

VOLUME 12 of Advances in Genetics exhibits very well both the strengths and also the weaknesses of this type of annual publication. In a total of nearly 400 pages it contains only four articles, of which the two longer concern general problems and the two shorter quite specialized and restricted special fields. The coverage is very wide, from the stringently intellectual molecular biology to the most 'biological' plant systematics and genetics. There is probably no biologist alive who will be equally interested in all four articles. It is worth considering what various types of readers can get out of them.

The first is by Frank Lanni on "The Biological Coding Problem". It is not more than about four years ago that the discovery by Nirenberg and Matthaei of cell-free protein synthesis in response to synthetic ribonucleotide polymers opened up any hopeful-looking avenues towards its solution. Now, Lanni's bibliography runs to about 400 titles, of which approximately 85 per cent are dated 1960 or later. This is in fact one of the big break-through salients on the biological front. The question that arises is: can any biologist not personally engaged in this particular foray find the time to follow, blow for blow, the course of the engagement? Moreover, will those who are engaged in it find here anything they did not know already? The immediate tactical situation is altering so rapidly that there are certainly some things which they will not find. For example, anyone who attended the recent Royal Society Mendel Centenary Celebrations in London will have heard Brenner argue that there must be a DNA codon for chain termination. I spent about half an hour looking for a reference to this in Lanni's article and failed to find it.

The next article is by $\mathrm{D}$. H. Davidson on differentiation in monolayer tissue culture cells. This is again a fashionable field but of a rather different kind. There has been no major theoretical break-through. It has been known for a very long time that cells in tissue culture tend "to lose their differentiation". Davidson's review contains at least 500 references, but of the 100 which I sampled, at least 60 were published before 1960 and as many as 50 before 1950 , quite a number of them going back before 1930. His article, in fact, gives a convincingly inclusive review of the present state of a complex and slowly advancing field.

The other two articles are of a quite different kind, both being devoted to authoritative summaries of specialized investigations in circumscribed fields. Verne Grant gives an account of the studies that have been made of a group of sibling species in the genus Gilia-small herbaceous plants common in western North America and South America. This is a valuable addition to the general body of knowledge about plant evolution. Oelkers summarizes the results of species crosses in the plant genus Streptocaparus, in which there have been many tantalizing indications of the importance of cytoplasmic factors. Our understanding of at least some types of cytoplasmic inheritance is being so rapidly advanced by studies on more genetically amenable forms, such as those of Sager on Chlamydomonas, that we are now faced with the challenge of passing well beyond the mere recognition of the existence of cytoplasmic factors; but this seems to be all that we can expect from the study of the more recalcitrant higher plants.

In sum, the new volume of Advances in Genetics well earns its place on the shelf of any well-stocked library. The first article will be extremely useful to a few people for a short time before it becomes out of date. The last three will be valuable to perhaps fewer people at any one time, but for a longer period.

C. H. WADDINGTON

\section{TETRAPYRROLE BIOSYNTHETICS}

Tetrapyrrole Biosynthesis and Its Regulation

By Dr. June Lascelles. (Microbial and Molecular Biology Series.) Pp. xii +132 . (New York and Amsterdam: W. A. Benjamin, Inc., 1964.) 7.70 dollars.

$\mathrm{D}$ R. JUNE LASCELLES has made important contributions over the past ten years to our knowledge of the synthesis of porphyrins and bacteriochlorophyll in photosynthetic micro-organisms and, in particular, of the factors concerned with the regulation of this process.

The most important part of Tetrapyrrole Biosynthesis and Its Regulation is a critical and informative discussion of the control of this ehain of reactions. However, this discussion, which forms chapter five of the book, is preceded by an account of the main structural features of tetrapyrroles, their physical properties and the methods used for the isolation and identification of both porphyrins and chlorophylls. A second chapter deals in a somewhat brief but concise manner with the distribution of haemoglobins in animal tissues. Dr. Lascelles considers, in more detail, the presence of the haemoglobins and especially of cytochromes in micro-organisms and in strictly anaerobic bacteria. She describes in a helpful manner the work which has been done, chiefly in the past few years, on the occurrence and probable function of the various cytochromes present in photosynthetic organelles and organisms.

Another section deals with the accumulation of porphyrins in micro-organisms, both of the photosynthetic and non-photosynthetic type; here it is of special interest that in most of these organisms it is coproporphyrin III which is present in relatively large amounts. A third chapter deals with the biosynthesis of tetrapyrroles, but this subject has been covered recently in a number of reviews. However, special emphasis is given here to work in micro-organisms, and the relationship between the biosynthesis of porphyrins and the more general metabolic reactions in the cell is emphasized.

Dr. Lascelles then deals with the chain of reactions leading from protoporphyrin to chlorophyll or bacteriochlorophyll. Many steps in this reaction sequence have been established, but there are many more for which no detailed information is available and for which enzymes have so far only been postulated. The structure of the chloroplast and that of the chromatophore is discussed in detail, and the important finding, which was mainly established by Dr. Lascelles and her colleagues, that the synthesis of bacteriochlorophyll and of protein is closely related, is rightly emphasized. However, as has already been stated, the most important part of the book is undoubtedly the chapter dealing with the control mechanisms, and this topic can be more easily investigated in micro-organisms than in animals.

The effect of light and oxygen tension has been known for some time, mainly due to the work of van Niel. Dr. Lascelles has herself contributed much to our understanding of the role of iron and she has also shown the repression of ALA synthetase by small amounts of haemin. Aminolaevulic acid itself appears to repress ALA synthetase, but it is likely that other reactions may also play a part in the overall regulation. Thus we still know very little about the availability of glycine or of succinyl co-enzyme $A$ or the importance of the methylation step in the overall regulation of the biosynthesis of chlorophylls by the cell.

There is obviously much more work to be done in this field, but the book by Dr. Lascelles not only reviews the present position fully but is also likely to stimulate many readers to do further investigations in this important field.
A. Neuberger 